\title{
Comparative Analysis of the 16S rRNA Gene Sequence of the Putative Agent of Proliferative Ileitis of Hamsters
}

\author{
TRACY A. PEACE, ${ }^{1} \dagger$ KENNY V. BROCK, ${ }^{2}$ AND HAROLD F. STILLS, JR. ${ }^{1 *}$ \\ Department of Veterinary Preventive Medicine, The Ohio State University, Columbus, Ohio 43210, ${ }^{1}$ and Ohio \\ Agricultural Research and Development Center, Food Animal Health Research Program, Wooster, Ohio $44691^{2}$

\begin{abstract}
Proliferative ileitis of hamsters is consistently associated with the presence of intracellular bacteria in affected ileal epithelial cells. The 16S rRNA gene sequence of the putative etiologic agent of proliferative ileitis was determined by using cell culture-maintained organisms. The highest level of relatedness $(\mathbf{9 8 . 4 \% )}$ was observed with a newly described obligately intracellular bacterium obtained from porcine intestines, and the level of homology with Desulfovibrio desulfuricans was $87.5 \%$.
\end{abstract}

Proliferative ileitis is a serious infectious disease of hamsters (Mesocricetus auratus) that is characterized by ileal epithelial hyperplasia and pyogranulomatous inflammation. Light microscopy and transmission electron microscopy have revealed that there are small curved intracellular bacteria within the apical cytoplasm of the ileal epithelial cells of hamsters with this disease. To date, attempts to propagate this organism on cell-free media have not been successful (19). The identity of this pathogen has not been determined, although it has been commonly associated with Campylobacter jejuni $(10,12)$.

In 1991, Stills isolated an intracellular bacterium from hamsters with proliferative ileitis, reproduced the disease in hamsters following oral inoculation with the organism, and reisolated the organism. Serologic evidence obtained from affected hamsters suggested that the organism was antigenically distinct from members of the genus Campylobacter and was probably not a member of this genus (19).

This study was undertaken to obtain definitive phylogenetic information about the agent of proliferative ileitis of hamsters, which remains uncharacterized. The fact that this obligately intracellular pathogen cannot be grown on artificial media precludes standard phenotypic characterization, making genotypic characterization essential. 16S rRNA gene sequencing and comparative sequence analysis were utilized to provide information concerning the phylogenetic position of this organism.

All cell lines were obtained from the American Type Culture Collection, Rockville, Md. The bacteria were grown in Intestine 407 human embryonic intestinal (ATCC CCL 6) cells and GPC-16 guinea pig colonic adenocarcinoma (ATCC CCL 242) cells by using the media and conditions described previously (19). Infected cell cultures were incubated until the host cell monolayer was destroyed, and culture supernatants were chilled and kept at $4^{\circ} \mathrm{C}$ until they were pelleted and purified. In each case the starting volume of culture supernatant was 1.5 liters.

The culture supernatant was clarified by low-speed centrifugation at $400 \times g$ for $10 \mathrm{~min}$ at $4^{\circ} \mathrm{C}$. The resulting supernatant was collected and centrifuged at $17,400 \times g$ for $12 \mathrm{~min}$ at $4^{\circ} \mathrm{C}$ to pellet the bacterial cells. The pellet was resuspended and

\footnotetext{
* Corresponding author. Present address: Department of Microbiology and Immunology, School of Medicine, Wright State University, 053 Health Science Bldg., Dayton, OH 45435. Phone: (513) 873-2792. Fax: (513) 879-2675. Electronic mail address: hstills@desire.wright. edu.

$\dagger$ Present address: Battelle Memorial Institute, Columbus, OH 43201 .
}

washed twice with equilibration buffer $(0.1 \mathrm{M} \mathrm{NaCl}, 0.01 \mathrm{M}$ phosphate $[\mathrm{pH} 6.8])$, and the bacteria were recovered by high-speed centrifugation following each wash. The resulting washed pellet was resuspended in $5 \mathrm{ml}$ of equilibration buffer and kept at $4^{\circ} \mathrm{C}$ prior to further purification.

Further purification of the bacterial cells from cellular debris was performed by anion-exchange chromatography with a DEAE-Sepharose CL-6B (Sigma Chemical Co., St. Louis, Mo.) column. The DEAE ion-exchange column was equilibrated with equilibration buffer. Following extensive washing of the column with equilibration buffer (until the level of absorbance reached the baseline value), the bacteria were eluted with elution buffer $(0.15 \mathrm{M} \mathrm{NaCl}, 0.01 \mathrm{M}$ phosphate [ $\mathrm{pH}$ 6.81) and then pelleted by high-speed centrifugation and suspended in phosphate-buffered saline. A small amount was examined with a modified Gram stain (in which carbol fuchsin replaced safranin) to assess purity.

Bacterial nucleic acid extraction, cDNA synthesis, and PCR amplification were performed as described previously (2). Three broadly useful 16S rRNA primers were used for PCR amplification, based on the work of Lane (9); these primers were designated 27f, 1386r, and 1492r. Primer 1386r was a slight modification of Lane's primer 1392r. The sequence of each of these primers is shown in Table 1. Primers $27 \mathrm{f}$ and 1386r comprised one pair of upstream-downstream primers, while primers $27 f$ and $1492 \mathrm{r}$ comprised a second pair. All primers were purchased from Genosys (The Woodlands, Tex.).

PCR amplification was performed with Vent polymerase (New England Biolabs, Inc., Beverly, Mass.) in a thermal cycler, using previously described methods (2). Following amplification, the PCR products were analyzed by electrophoresis in $1 \%$ agarose in $1 \times$ Tris-acetate buffer. One of the PCR products was purified as previously described (16) and then $\mathrm{C}$ tailed by using a commercially available kit (DNA Tailing Kit; Boehringer Mannheim, Indianapolis, Ind.). The C-tailed PCR product was ligated into a G-tailed PstI-cut pUC9 plasmid vector (18) and used to electrotransform Escherichia coli JM109 competent cells. Transformed strain JM109 cells were plated onto YT media containing ampicillin, 5-bromo-4-chloro-3-indolyl- $\beta$-D-galactopyranoside (X-Gal), and isopropyl- $\beta$-D-thiogalactopyranoside (IPTG) (8), and white putatively recombinant colonies were selected. Putatively recombinant colonies were screened by two methods: colony hybridization and restriction enzyme digestion of plasmid minipreparations. Colony hybridization was performed by previously described methods (18). PstI was obtained from New England Biolabs, Inc.

The plasmid DNA used for sequencing was extracted and 
TABLE 1. PCR and sequencing primers

\begin{tabular}{llcc}
\hline Primer & \multicolumn{1}{c}{ Primer sequence } & $\begin{array}{c}\text { Used for } \\
\text { PCR }\end{array}$ & $\begin{array}{c}\text { Used for } \\
\text { sequencing }\end{array}$ \\
\hline 27f & AGAGTTTGATCCTGGCTCAG & + & + \\
470f & GGTCTATTTTGACGGTA & & + \\
519r & GWATTACCGCGGCKGCTG & & + \\
907r & CCGTCAATTCMTTTRAGTTT & & + \\
1022r & CTGTCTTGAGGCTCCCGA & + & + \\
1386r & TGACGGGCGGTAGAGTACA & + & + \\
$1492 \mathrm{r}$ & TACGGYTACCTTGTTACGACTT & + & + \\
\hline
\end{tabular}

purified by alkaline lysis and polyethylene glycol precipitation (1) and then denatured. Nucleotide sequencing was performed with a Sequenase 2.0 DNA sequencing kit (United States Biochemical Corp., Cleveland, Ohio), using ${ }^{35}$ S-labeled dATP (Amersham Corp., Arlington Heights, Ill.). Nine sequencing primers were utilized; the designations and sequences of seven of these primers are shown in Table 1 . The two other primers used were universal sequencing primer M13 $(-40)$ and reverse primer M13 (United States Biochemical Corp.). Primers 470f and $1022 \mathrm{r}$ were constructed following initial nucleotide sequence data collection and evaluation, with the assistance of a computer program (OLIGO; National Biosciences, Plymouth, Minn.). Nucleotide sequence comparison and analysis were accomplished by using HIBIO DNASIS (Hitachi Software Engineering Co., Ltd., Brisbane, Calif.). The services of the Ribosomal RNA Database Project (17) and GenBank were utilized for homology searches. The services of the Ribosomal RNA Database Project were also used for phylogenetic tree generation.

The results of agarose gel electrophoresis of the PCR products revealed a single band for each pair of PCR primers (approximately 1,400 bases for the 27f-1386r pair and 1,500 bases for the $27 \mathrm{f}-1492 \mathrm{r}$ pair). The $27 \mathrm{f}-1492 \mathrm{r}$ PCR product was cloned and screened for recombinant colonies. Three colonies were positive for colony hybridization. Restriction enzyme digests of plasmid minipreparations prepared from these three colonies revealed that each had a band of the correct size. The complete 16S rRNA sequence was determined by sequencing all three clones. A consensus base was identified for each position.

In this paper we describe the nucleotide sequence and the results of a comparative sequence analysis of the $16 \mathrm{~S}$ rRNA gene of the putative agent of proliferative ileitis of hamsters. Our results have important implications for the formal identification of this pathogen, which currently cannot be propagated on artificial media or characterized by phenotypic means.

Although proliferative ileitis has been associated with campylobacters for many years, our results demonstrate that the causative organism is phylogenetically related to the genus Desulfovibrio (a genus of dissimilatory sulfate-reducing bacteria) and to the newly described obligately intracellular bacteria of porcine intestines, for which the vernacular name "ileal symbiont intracellularis" has been proposed (6).

Our search for relatedness began by utilizing the services of the Ribosomal RNA Database Project (17). Using mail server commands, we requested a similarity rank (with a list length of 10) for our single-stranded unknown rRNA. The similarity rank function calculates the number of oligomers that an unknown sequence has in common with the sequences in the database and expresses the result or score as a percentage of the total number of shared oligomers. It is thought that scores
TABLE 2. Similarity rank scores obtained with data from the Ribosomal RNA Database Project

\begin{tabular}{|c|c|}
\hline Score $(\%)$ & Taxon \\
\hline \multicolumn{2}{|c|}{$52.9 \ldots \ldots \ldots . . . . . .$. Desulfovibrio desulfuricans } \\
\hline \multicolumn{2}{|c|}{45.1 ............... Desulfomonas pigra } \\
\hline \multicolumn{2}{|c|}{ 43.7 ...............Desulfovibrio vulgaris $\mathrm{Hi}$} \\
\hline \multicolumn{2}{|c|}{$40.3 \ldots \ldots \ldots \ldots \ldots$ Desulfovibrio salexigens } \\
\hline \multicolumn{2}{|c|}{$39.0 \ldots \ldots \ldots \ldots . . .$. Desulfovibrio africanus } \\
\hline \multicolumn{2}{|c|}{38.8 .................. Desulfovibrio gigas } \\
\hline \multicolumn{2}{|c|}{ 37.4 ..................... esulfovibrio longus SEBR 2582} \\
\hline \multicolumn{2}{|c|}{$36.9 \ldots \ldots \ldots \ldots$........... Desulfuromonas acetoxidans 11070 or 5071} \\
\hline & ...Desulfomicrobium baculatus DSM 1743 \\
\hline & desulfuricanc Norua \\
\hline
\end{tabular}

of $25 \%$ or less reflect universal commonality of rRNA and not true affiliation (17).

The similarity rank results generated with our data are shown in Table 2. The highest score, $52.9 \%$, occurred with Desulfovibrio desulfuricans. The complemented sequence scores were low, as expected, ranging from 2.7 to $3.2 \%$ (data not shown).

The phylogenetic tree generated with the similarity rank data obtained from the Ribosomal RNA Database Project is shown in Fig. 1. Again, a close relationship with the genus Desulfovibrio and other sulfate-reducing bacteria is evident.

After we obtained Ribosomal RNA Database Project homology information, DNA homology searches were performed with $16 \mathrm{~S}$ rRNA gene sequences downloaded from GenBank by using the HIBIO DNASIS program. The organisms whose $16 \mathrm{~S}$

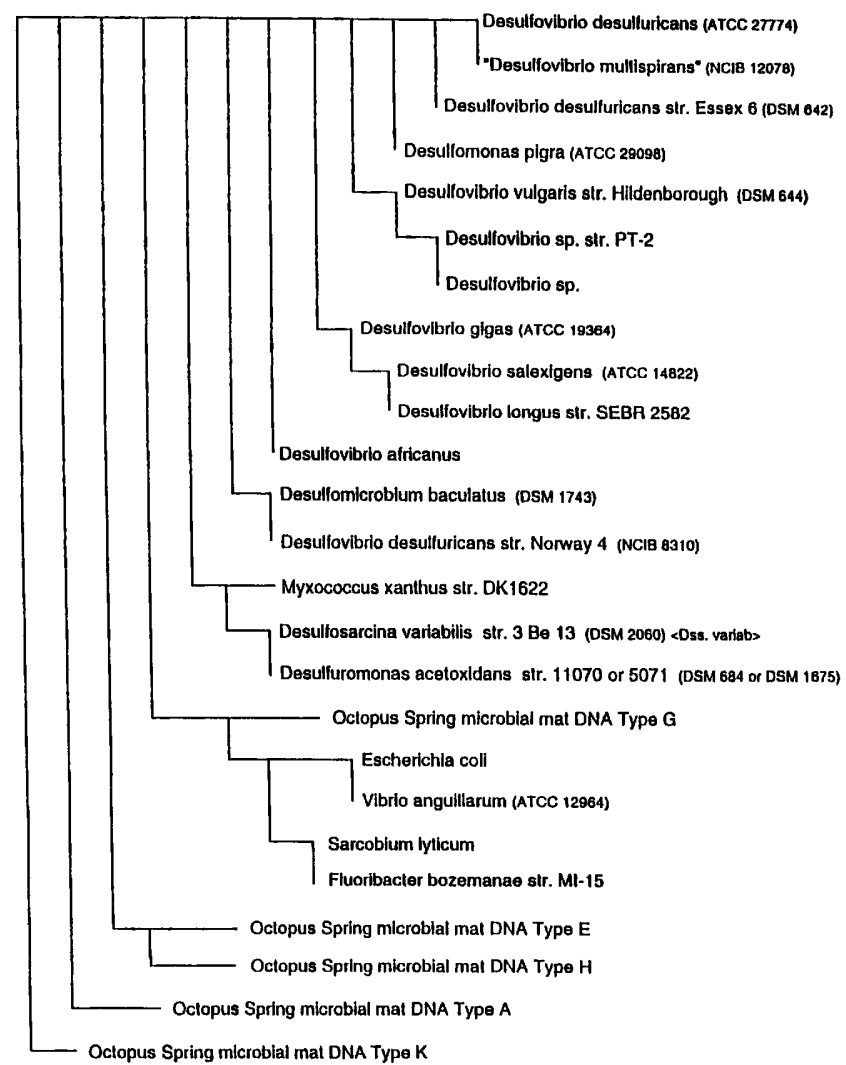

FIG. 1. Phylogenetic tree based on similarity rank data obtained from the Ribosomal RNA Database Project. 
TABLE 3. Levels of homology between the 16S rRNA gene sequence of the putative agent of hamster proliferative ileitis and the $16 \mathrm{~S}$ rRNA gene sequences of selected bacteria

\begin{tabular}{llc}
\hline \multicolumn{1}{c}{ Species } & $\begin{array}{c}\text { Accession } \\
\text { no. }\end{array}$ & $\begin{array}{c}\% \\
\text { Homology }\end{array}$ \\
\hline "Ileal symbiont intracellularis"a & L15739 & 98.4 \\
Desulfovibrio desulfuricans & M34113 & 87.5 \\
Chlamydia psittaci & M13769 & 73.7 \\
Borrelia burgdorferi & X57404 & 72.5 \\
Treponema phagedenis & M57739 & 72.3 \\
Rickettsia prowazeki & M21789 & 69.4 \\
Campylobacter jejuni & L04315 & 67.1 \\
Campylobacter fetus & L04314 & 66.9 \\
Campylobacter coli & L04312 & 66.8 \\
Helicobacter felis & M57398 & 66.7 \\
Campylobacter hyointestinalis & M65009 & 65.7 \\
\hline
\end{tabular}

${ }^{a}$ Proposed vernacular name.

rRNA gene sequences were obtained from GenBank were chosen for several reasons, including (i) they had high Ribosomal RNA Database Project similarity rank scores, (ii) they were known gastrointestinal pathogens, (iii) they were known members of the gastrointestinal flora, (iv) they were organisms that have historically been associated with proliferative ileitis of hamsters (campylobacters), (v) they were able to grow intracellularly in epithelial cells, or (vi) they were associated with proliferative enteropathies of other species.

The highest level of homology observed was with the "ileal symbiont intracellularis" 16S rRNA gene, whose sequence exhibited a level of homology of $98.4 \%$ with our sequence. "Ileal symbiont intracellularis" was also related to Desulfovibrio species; its 16S rRNA sequence was most similar to the D. desulfuricans ATCC 27774 sequence (level of homology, 91\%) (6). The organisms examined, their accession numbers, and the levels of homology between their 16S rRNA genes and our $16 \mathrm{~S}$ rRNA gene are shown in Table 3.

"Ileal symbiont intracellularis" has been described as a new genus and species of obligately intracellular bacteria that are found in porcine intestines (6). The findings of Gebhart et al. (6) provided evidence that these bacteria are not members of currently described genera and that they belong to the delta subdivision of the Proteobacteria.

In addition to hamsters and pigs, other species of animals, including ferrets and rabbits, naturally develop proliferative enteropathies. The proliferative enteropathies of these species exhibit similar pathology; the lesions include replacement of normal gut epithelium with immature proliferating epithelium, and intracellular microorganisms are present in the apical cytoplasm of affected cells $(5,11,14)$. The results of serologic studies and DNA analysis have suggested that the intracellular campylobacter-like organisms found in these proliferative enteropathies represent novel bacteria with significant differences from the campylobacters commonly associated with this disease $(4,13,15)$.

On the basis of our 16S rRNA sequence data and comparative analysis data we could not identify the organism which we studied as a member of a particular species, but the data did allow us to define generic relationships and provided evidence that proliferative ileitis of hamsters is not caused by a Campylobacter species.

The results of previous studies, coupled with new genotypic information, are changing the focus of studies of the etiology of proliferative ileitis of hamsters. The causative agent appears to be related to the genus Desulfovibrio and to the newly described organism "ileal symbiont intracellularis."
The information described above suggests that the proliferative enteropathies of hamsters and swine are caused by closely related organisms. Additional molecular analyses must be performed before the etiologic agent of proliferative ileitis of hamsters can be fully described. Oligodeoxynucleotide hybridization probes must be synthesized on the basis of the known rRNA sequence to detect the organism in situ. Such hybridization probes have been used to identify individual species, as well as phylogenetic groups of cultured and uncultured organisms $(3,7)$. Finally, there must be continued attempts to grow the organism on artificial media to allow phenotypic characterization and fulfillment of Koch's postulates.

Nucleotide sequence accession number. The nucleotide sequence which we determined in this study has been deposited in the GenBank data library under accession number U06423.

This work was supported in part by a grant from the National Pork Producers Council (to H.F.S.).

\section{REFERENCES}

1. Ausubel, F. M., R. Brent, R. E. Kingston, D. D. Moore, J. G. Seidman, J. A. Smith, and K. Struhl (ed.). 1987-1990. Current protocols in molecular biology, vol. 1, supplement 8 . Wiley Interscience, New York.

2. Brock, K. V., R. Deng, and S. Riblet. 1992. Nucleotide sequencing of $5^{\prime}$ and $3^{\prime}$ termini of bovine viral diarrhea virus by RNA ligation and PCR. J. Virol. Methods 38:39-46.

3. Distel, D. L., E. F. DeLong, and J. B. Waterbury. 1991. Phylogenetic characterization and in situ localization of the bacterial symbiont of shipworms (Teredinidae: Bivalvia) by using $16 \mathrm{~S}$ rRNA sequence analysis and oligodeoxynucleotide probe hybridization. Appl. Environ. Microbiol. 57:2376-2382.

4. Fox, J., F. E. Dewhirst, B. J. Paster, and B. Shames. 1993. Identification of the uncultured intracellular campylobacter-like organism in proliferative bowel disease of ferrets and hamsters. Contemp. Top. Lab. Anim. Sci. 32:7.

5. Fox, J. G., and G. H. K. Lawson. 1988. Campylobacter-like omega intracellular antigen in proliferative colitis of ferrets. Lab. Anim. Sci. 38:34-36.

6. Gebhart, C. J., S. M. Barns, S. McOrist, G.-F. Lin, and G. H. K. Lawson. 1993. Ileal symbiont intracellularis, an obligate intracellular bacterium of porcine intestines showing a relationship to Desulfovibrio species. Int. J. Syst. Bacteriol. 43:533-538.

7. Giovannoni, S. J., E. F. DeLong, G. J. Olsen, and N. R. Pace. 1988. Phylogenetic group-specific oligodeoxynucleotide probes for identification of single microbial cells. J. Bacteriol. 170:720-726.

8. Heidecker, G., and J. Messing. 1983. Sequence analysis of zein cDNAs obtained by an efficient mRNA cloning method. Nucleic Acids Res. 11:4891-4906.

9. Lane, D. J. 1991. 16S/23S rRNA sequencing, p. 115-147. In E. Stackebrandt and M. Goodfellow (ed.), Nucleic acid techniques in bacterial systematics. John Wiley and Sons, Chichester, England.

10. LaRegina, M., and J. Lonigro. 1982. Isolation of Campylobacter fetus subspecies jejuni from hamsters with proliferative ileitis. Lab. Anim. Sci. 32:660-662.

11. Lawson, G. H. K., A. C. Rowland, and N. MacIntyre. 1985. Demonstration of a new intracellular antigen in porcine intestinal adenomatosis and hamster proliferative ileitis. Vet. Microbiol. 10:303-313.

12. Lentsch, R. H., R. M. McLaughlin, J. E. Wagner, and T. J. Day. 1982. Campylobacter fetus subspecies jejuni isolated from Syrian hamsters with proliferative ileitis. Lab. Anim. Sci. 32:511-514.

13. McOrist, S., R. Boid, and G. H. K. Lawson. 1989. Antigenic analysis of Campylobacter species and an intracellular Campylobacter-like organism associated with porcine proliferative enteropathies. Infect. Immun. 57:957-962.

14. McOrist, S., and G. H. K. Lawson. 1987. Possible relationship of proliferative enteritis in pigs and hamsters. Vet. Microbiol. 15: 293-302.

15. McOrist, S., G. H. K. Lawson, D. J. Roy, and R. Boid. 1990. DNA analysis of intracellular campylobacter-like organisms associated 
with the porcine proliferative enteropathies: a novel organism proposed. FEMS Microbiol. Lett. 69:189-194.

16. Mukhopadyay, T., and J. A. Roth. 1991. A simple and efficient method for isolation of DNA fragments from agarose gel. Nucleic Acids Res. 19:6656.

17. Olsen, G. J., R. Overbeek, N. Larsen, T. L. Marsh, M. J. McCaughey, M. A. Maciukenas, W.-M. Kuan, T. J. Macke, Y. Xing, and C. R. Woese. 1992. The Ribosomal Database Project.
Nucleic Acids Res. 20:2199-2200.

18. Sambrook, J., E. F. Fritsch, and T. Maniatis. 1989. Molecular cloning: a laboratory manual, 2nd ed. Cold Spring Harbor Laboratory Press, Cold Spring Harbor, N.Y.

19. Stills, H. F. 1991. Isolation of an intracellular bacterium from hamsters (Mesocricetus auratus) with proliferative ileitis and reproduction of the disease with a pure culture. Infect. Immun. 59:3227-3236. 